piston against the cover. When this happens a high pressure is rapidly developed and the current is broken. The total amount of gas produced depends on the energy dissipated in the are and formulæ to determine this energy are given.

Recently there has been a revival of interest in water circuit-breakers. They have the advantage of not using an inflammable liquid but they do not eliminate the danger of explosion, since if the are is not broken quickly enough, steam is produced in such quantities that the breaker blows up.

The compressed air breaker works satisfactorily as the pressure does not exceed a definite value, but a compressed air plant is necessary to operate it. Breakers without oil based on the principle of the action of a magnetic field on the arc have many advantages but on account of difficulties in insulation they cannot be used in practice with high voltages. Oscillograms are shown of how the current varies when different kinds of experimental breakers are in action.

\section{Climate of Hong-Kong}

"T HE Climate of Hong-Kong", by T. F. Claxton, published by the Royal Observatory, HongKong, as an appendix to the ordinary annual summary of Hong-Kong observations for 1931, is one of the most complete accounts of the climate of a station in the Far East. It summarises and discusses the observations made from 1884 to 1929 . Most of the tables are in the form in which the mean value of a meteorological ele. ment, for example, atmospheric pressure, temperature, etc., for each hour is shown for each calendar month, the minimum hourly value of each element being taken as zero while the other values are expressed as departures therefrom in the customary units. A collection of tables of this kind makes a very indigestible meal for all except the expert meteorologist and for this reason the explanatory discussion is very welcome, particularly the general discussion of the seasons.

The seasonal rhythm in Hong-Kong is, of course, greatly influenced by the Asiatic monsoon. Lying practically on the Tropic of Cancer, the northeast monsoon in the winter does not give rise to much cold weather; a minimum temperature of $45^{\circ}$ is reckoned a low one, while an afternoon maximum of $75^{\circ}$, for which in England one sometimes must wait until nearly the middle of the summer, is not rare in January. Mist and fog are of common occurrence in the period of rapidly rising temperature around March, generally when pressure is falling over China and the north-east monsoon is weakening; much of it is due to dynamical cooling of advancing damp southerly winds. The summer, with its mean temperature of $82^{\circ} \mathrm{F}$., is characterised by unsteady winds, rather frequent thunder storms and heavy rain; the destructive effects of a typhoon are occasionally felt, more especially in late August. October brings back the north-east monsoon, and, generally, fine dry weather leading back through a quickly falling temperature to the winter.

There is a considerable section devoted to the discussion of typhoons, containing a number of important statistical tables, and the non-tabular part of the work ends with an interesting item seldom to be found in works of this kind-an account of the principal empirical rules of weather forecasting for the region under discussion.

\section{University and Educational Intelligence}

London.-The Clothworkers' Company, the Grocers' Company, the Drapers' Company and the Skinners' Company has each decided to make very generous grants to the University in the shape of annual payments extending over a series of years. These grants will amount in all to $£ 20,000$ from the Clothworkers' Company, $£ 10,000$ from the Grocers' Company, $£ 5,000$ from the Drapers' Company, to whose munificent help for East London College the University is already greatly indebted, and $£ 5,000$ from the Skinners' Company. As in the case of the grants already announced from the Corporation of the City of London, from the Mercers' Company and from the Fishmongers' Company, these benefactions will be applied towards meeting the cost of the new Ceremonial Hall to be erected on the University's site in Bloomsbury.

A course of ten lectures on alternating currents and electrical oscillations will be given by Dr. D. Owen, head of the Department of Physics and Mathematics of the Sir John Cass Technical Institute, at the Institute, Jewry Street, Aldgate, London, E.C.3, on Tuesday evenings commencing on January 31. The lectures will be accompanied by practical demonstrations. Further information can be obtained from Dr. Owen at the Institute.

The school magazine coming from Stowe School, entitled the Stoic, is a sumptuously printed and illustrated record of extra-curricular activities among which film exhibitions have an important place. The school was one of the first to have a full-size silent projector and to change over to sound. Its recently founded Film Society aims at contributing towards the development of the art of the cinema by helping to prepare (in the words of the headmaster's inaugural speech) a forward-looking and active-minded public waiting to welcome the work of exploration through this medium of undiscovered territory of the mind. It is worthy of note that, in the list of films exhibited during last term, there are none of the professedly instructional type.

Statistics of secondary schools in the United States, published in a recent bulletin of the Office of Education, Washington, show an aggregate enrolment in 1930 of more than five million - roughly half of the population of secondary school age. The schools tend to increase in size, the average enrol ment having increased from 211 in 1926 to 234 in 1930. Five per cent of them had, in the latter year, more than 1,000 pupils; 27 in New York and Chicago had more than 5,000, the largest of all having more than 10,000 pupils. Re-organisations, involving the incorporation in the secondary school scheme of some of the years previously covered by elementary school courses, have made considerable headway in recent years, especially in schools with from 300 to 2,500 pupils, two-thirds of which have now been re-organised. The proportion of men to women teachers in secondary schools, except in those for negroes, shows a tendency to increase. School libraries have increased in size steadily; the average number of volumes has risen from 1,652 in 1926 to 2,000 in 1930 . 